\title{
Research on the Mathematical Modeling of Damping Controlled Oil Gas Spring
}

\author{
Yijie Chen*, Yafeng Zhang, Mengyan Xu, Fu Du and Peng Gui \\ China North Vehicle Research Institute, Beijing, China \\ ${ }^{*}$ Corresponding author
}

\begin{abstract}
In order to improve the vehicle performance, the mathematical model and experimental research of damping controlled oil gas spring were carried out in this paper, a proportional throttle valve was installed on the basis of the original damping valve system. The proportional valve adopted slide valve structure and had 15 gear adjustment positions, through regulating the current intensity to achieve the purpose of controlling valve opening and flow. After that, the flow coefficient was fitted by comparing the valve flow through the flow test, which could make the analytical calculation of damping characteristics realize conveniently. Compared with the experimental data, the maximum calculation error could be controlled to $5.6 \%$.
\end{abstract}

Keywords-damping controlled; oil gas spring; proportional valve; mathematical modeling

\section{INTRODUCTION}

For the passive suspension, when the damping valve structure parameters was determined, the system output force cannot be adjusted in a large range, and the mobility and manipulation stability are difficult to achieve to the ideal condition on different road conditions and the vehicle speed ${ }^{[1]}$. According to the semi-active suspension structure principle, the electromagnetic proportional control valve is mounted outside the oil gas spring for using the high pressure pipeline, and it connects parallel with damping valve. The control valve throttle area could be adjusted through changing the current intensity, and the damping force also could be changed following the current.

\section{STRUCTURE AND WORKING PRINCIPLE}

As shown in FIGURE $I$, it is oil gas spring structure diagram. Control valve connected to upper and lower chambers of the oil gas spring through pressure pipelines. The damping valve with throttle slice was mounted inside the piston, when the piston reciprocating movement, throttle slice will be deformed because differential pressure of upper and lower chamber. The oil and nitrogen were isolated by floating piston, and the gas chamber length was changed through the oil gas spring displacement.

As shown in FIGURE II, it is oil gas spring equivalent flow diagram.In which $Q$ is oil gas spring flow, $Q_{k}$ is the control valve flow, $Q_{f}$ is damping valve flow, $Q_{g}$ is passing oil orifice flow, and $Q_{\mathrm{gk}}$ is the high pressure pipeline flow.

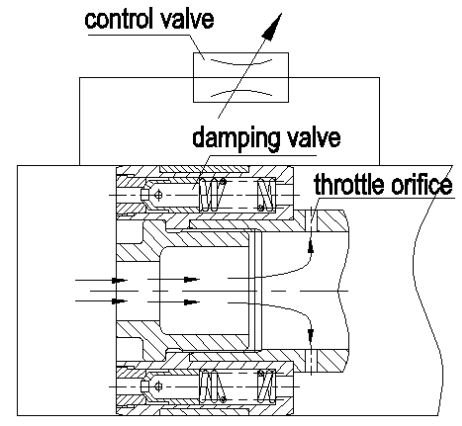

FIGURE I. OIL GAS SPRING STRUCTURE DIAGRAM

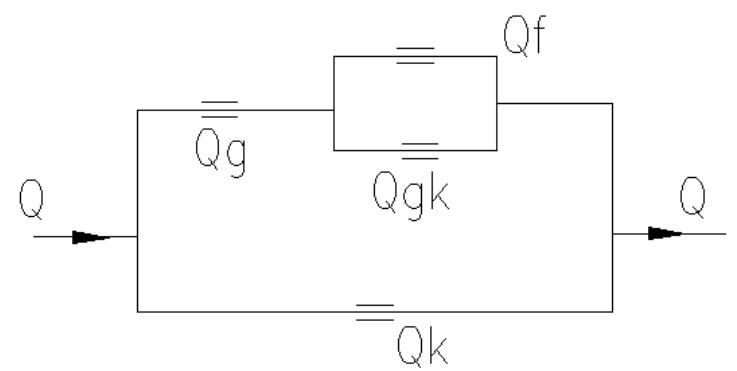

FIGURE II. OIL GAS SPRING EQUIVALENT FLOW DIAGRAM.

\section{MAthmaticAl MOdel OF SEMI ACTIVE SUSPENSION}

\section{A. Flow and Differential Pressure of Control Valve}

In FIGURE III, it is the structure of control valve, which mainly control the output force through changing the current, and the pressure difference is produced by the local resistance loss when oil flow the passage which is indicated by arrow in the figure. The regulating current accuracy of control valve is $I=0.1 \mathrm{~A}$. When $I=0 \mathrm{~A}$, the orifice area maximum, the output force minimum, it is suitable for vehicle traveling on a flat road, to improve the comfort. When $I=1.5 \mathrm{~A}$, the control valve is closed, and only the damping valve work normally, system output force maximum, it is suitable for vehicle running on the rough road, in order to ensure the driving safety. 


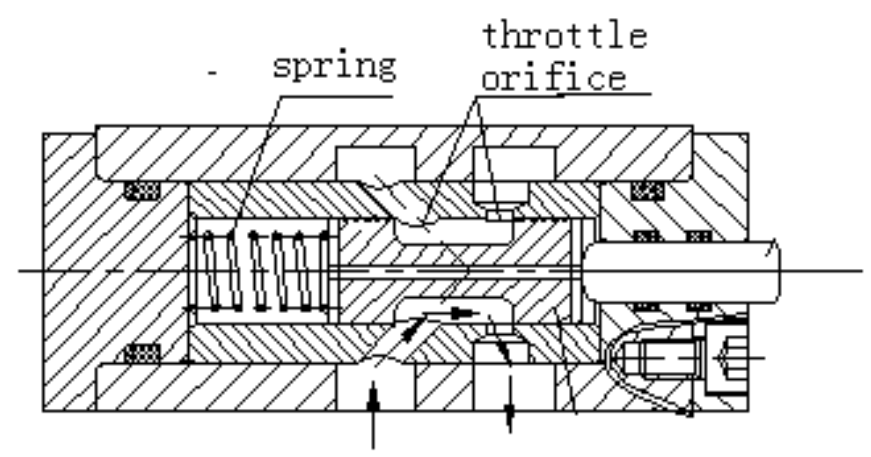

FIGURE III. STRUCTURE OF CONTROL VALVE

Because the control valve of oil flow passage is more complex, so it is difficult to accurate analyze the flow field structure using analytic method. In this article, the least square method is used to fit the test data curve of control valve, and the following function expression is selected for parameter approximation $^{[2-4]}$ :

$$
Q_{\mathrm{k}}=C_{\mathrm{k}} \sqrt{\frac{2 \Delta p_{\mathrm{k}}}{\rho}}
$$

In which, $C_{\mathrm{k}}$ is control valve flow coefficient.

The flow residual error square expression is:

$$
\Pi=\sum_{i=1}^{n}\left(Q_{\mathrm{k}}-Q_{\mathrm{ki}}\right)^{2}=\sum_{i=1}^{n}\left(C_{\mathrm{k}} \sqrt{\frac{2 \Delta p_{\mathrm{k} i}}{\rho}}-Q_{\mathrm{k} i}\right)^{2}
$$

In which, $Q_{\mathrm{k} i}$ is control valve flow test data, $\Delta p_{\mathrm{k} i}$ is the pressure difference of test data, $i(1,2 \cdots n)$ is a data group.

$$
\frac{\partial \Pi}{\partial C_{\mathrm{k}}}=2 \sum_{i=1}^{n} \sqrt{\frac{2 \Delta p_{\mathrm{k} i}}{\rho}}\left(C_{\mathrm{k}} \sqrt{\frac{2 \Delta p_{\mathrm{ki}}}{\rho}}-Q_{\mathrm{k} i}\right)=0
$$

The flow coefficient formula is:

$$
C_{\mathrm{k}}=\sqrt{\frac{\rho}{2}} \sum_{i=1}^{n} \frac{Q_{\mathrm{k} i}}{\sqrt{\Delta p_{\mathrm{k} i}}}
$$

The test data curve fitting is shown in FIGURE IV, and control valve flow coefficient of different current is shown in TABLE I.
TABLE I. CONTROL VALVE FLOW COEFFICIENT OF DIFFERENT CURRENT

\begin{tabular}{|c|c|c|c|}
\hline$I / \mathrm{A}$ & 0 & 0.3 & 1.5 \\
\hline$C_{\mathrm{k}} / \mathrm{mm}^{2}$ & 12.69 & 9.92 & 0 \\
\hline
\end{tabular}

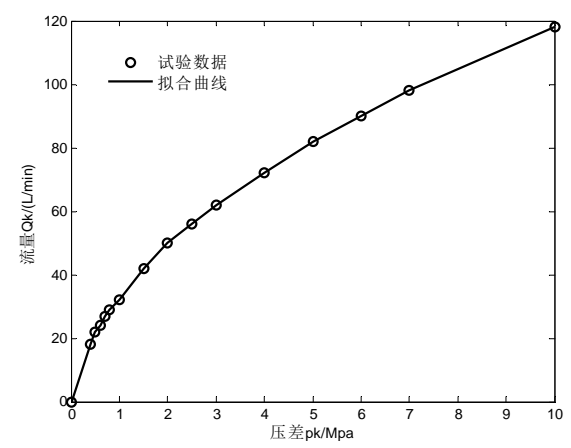

FIGURE IV. THE TEST FITTING CURVE OF CONTROL VALVE

B. Units Damping Force of Semi Active Oil Gas Spring The gap flow fomula is:

$$
Q_{\mathrm{f}}=\frac{\pi r_{\mathrm{n}} \Delta p \delta^{3}}{6 \mu n h}
$$

In which, $\mu$ is oil dynamic viscosity, $n$ is the number of valve slice, $h$ is the slice thickness, $r_{n}$ is the outer radius, $\Delta p$ is total pressure of oil gas spring, $\delta$ is annular gap width.

The total pressure of oil gas spring is:

$$
\left\{\begin{array}{l}
\Delta p=\Delta p_{\mathrm{f}}=\Delta p_{\mathrm{k}} \\
A_{\mathrm{u}} V_{\mathrm{d}}=\frac{\pi r_{\mathrm{n}} \Delta p \delta^{3}}{6 \mu n h}+C_{\mathrm{k}} \sqrt{\frac{2 \Delta p}{\rho}}
\end{array}\right.
$$

In which, $A_{u}$ is the piston area, $V_{d}$ is the piston velocity, $\rho$ is the oil liquid density.

And the differential pressure is:

$$
\Delta p=\frac{6 \mu n h}{\pi r_{\mathrm{n}} \delta^{3}}\left(A_{\mathrm{u}} V_{\mathrm{d}}-Z_{2}\right)
$$

In which,

$$
Z_{1}=\sqrt{18 C_{\mathrm{k}}^{2} \mu^{2} n^{2} h^{2}+6 \pi r_{\mathrm{n}} \rho \delta^{3} A_{\mathrm{u}} V_{\mathrm{d}} \mu n h}
$$




$$
Z_{2}=\frac{C_{\mathrm{k}}\left(-6 \sqrt{2} C_{\mathrm{k}} \mu n h+2 Z_{1}\right)}{\sqrt{2} \pi r_{\mathrm{n}} \rho \delta^{3}}
$$

The slice turbulent flow formula:

$$
Q_{\mathrm{f}}=2 \pi r_{\mathrm{n}}\left\{-127.79 v+\left[3+2.5 \ln \left(\sqrt{\frac{\Delta p \delta^{3}}{8 v^{2} n h \rho}}\right)\right] \sqrt{\frac{\Delta p \delta^{3}}{2 n h \rho}}\right\}
$$

The total pressure difference of semi active suspension is:

$$
\left\{\begin{array}{l}
Z_{3}=127.79 v+\frac{A_{\mathrm{g}}}{2 \pi r_{\mathrm{n}}} \sqrt{\frac{2 \Delta p_{\mathrm{g}}}{\xi_{\mathrm{g}} \rho}} \\
Z_{3}=\frac{A_{\mathrm{u}} V_{\mathrm{d}}-C_{\mathrm{k}} \sqrt{\frac{2 \Delta p_{\mathrm{k}}}{\rho}}}{2 \pi r_{\mathrm{n}}}+127.79 v \\
\Delta p_{\mathrm{k}}=\left(\frac{A_{\mathrm{gk}}}{C_{\mathrm{k}}}\right)^{2} \frac{\Delta p_{\mathrm{gk}}}{\xi_{\mathrm{gk}}} \\
\Delta p=\Delta p_{\mathrm{f}}+\Delta p_{\mathrm{g}}=\Delta p_{\mathrm{k}}+\Delta p_{\mathrm{gk}}
\end{array}\right.
$$

In which, $A_{\mathrm{g}}$ is passing oil orifice cross-sectional area, $A_{\mathrm{gk}}$ is cross-sectional area of pressure pipeline, $\xi_{\mathrm{gk}}$ is the local resistance loss coefficient, $\xi_{g}$ is the local resistance loss coefficient of passing oil orifice.

\section{The Test And Simulation}

TABLE II.

$$
\text { KEY POINT FORCE WHEN CURRENT } I=1.5 \mathrm{~A}
$$

\begin{tabular}{|c|c|c|c|c|}
\hline The foce name & $F_{z \max }$ & $F_{z \text { min }}$ & $F_{z y 0}$ & $F_{z f 0}$ \\
\hline Test data $(\mathrm{kN})$ & 56.99 & 11.29 & 41.44 & 17.23 \\
\hline Simulation data $(\mathrm{kN})$ & 57.55 & 11.95 & 41.63 & 16.54 \\
\hline Data error (\%) & 0.97 & 5.52 & 0.46 & 5.6 \\
\hline
\end{tabular}

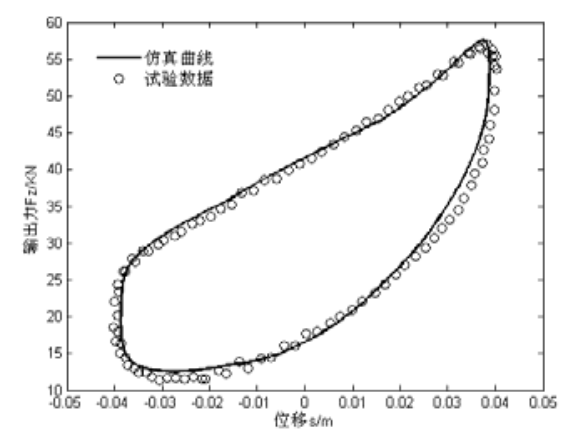

FIGURE V. THE TEST FITTING CURVE OF CONTROL VALVE
From the above chart can be seen, the deviation of simulation results and experimental data is very small, and it is verified that oil gas spring mathematical model and the control valve data fitting method are correct.

\section{REFERENCES}

[1] Kwangjin Lee, "Numerical modelling for the hydraulic performance prediction of automotive monotube dampers”, Vehicle System Dynamics, in press.

[2] Chen Yijie, "Research on Analytical Computation of Valve Parameters and Design of Hydro-pneumatic Spring”, Beijing Institute of Technology, in press.

[3] ByungYoung Moona, Kawabata Showa, SungWon Chung, "Mechanical properties study and design of a suspension system by considering tension force”, Materials Processing Technology, in press.

[4] Chen Yijie, Gu Liang, Guan Jifu, "Research on the mathematical model and analysis the throttle aperture of hydro-pneumatic spring”, Beijing Institute of Technology, in press. 